\title{
Speaking with different voices: the problems with English law and psychiatric injury
}

\author{
Russell Orr* \\ University of Westminster
}

Private law courts in the UK have maintained the de minimis threshold as a condition precedent for a successful claim for the infliction of mental harm. This de minimis threshold necessitates the presence of a 'recognised psychiatric illness' as opposed to 'mere emotion'. This standard has also been adopted by the criminal law courts when reading the Offences Against the Person Act 1861 to include non-physical injury. In determining the cut-off point between psychiatric injury and mere emotion, the courts have adopted a generally passive acceptance of expert testimony and the guidelines used by mental health professionals to make diagnoses. Yet these guidelines were developed for use in a clinical setting, not a legal one. This paper examines the difficulty inherent in utilising the 'dimensional' diagnostic criteria used by mental health professionals to answer 'categorical' legal questions. This is of particular concern following publication of the new diagnostic manual, DSM-V, in 2013, which will further exacerbate concerns about compatibility. It is argued that a new set of diagnostic guidelines, tailored specifically for use in a legal context, is now a necessity.

Dr Russell Orr, University of Westminster, Westminster Law School, 4-16 Little Titchfield Street, LondonW1W 7BY, UK. Email: r.orr@westminster.ac.uk

\section{INTRODUCTION}

In Whitmore $v$ Euroways Express Coaches $L t d,{ }^{1}$ a case that involved a claim for nervous shock, Comyn J was willing to relax what had become a central component of English law regarding such claims and awarded damages following the onset of 'ordinary shock'. While certain academic and judicial commentators may now conclude that this was an astute observation leading to an easily defensible decision in keeping with emerging common law precedents in other jurisdictions, ${ }^{2}$ the Law Commission has described it as an 'aberration' 3 and has lent its full support to the maintenance of the orthodox standard. ${ }^{4}$ The sacred rule in English private law that Comyn J was willing to disregard concerns the definition of 'nervous shock' itself, and represents the minimum threshold that must be reached before an individual may seek to recover damages. As Lord Denning observed in Hinz v Berry, this term has been employed by the court to cover any 'recognisable psychiatric illness'. This notion of a 'recognisable

* I would like to acknowledge Dr Ciara Hackett for her thoughtful assistance with the preparation of this manuscript.

1. 'Whitmore v Euroways Express Coaches Ltd' The Times 4 May 1984.

2. NJ Mullany and PR Handford Tort Liability for Psychiatric Damage (Sydney: Law Book Company, 1993) pp 18-21.

3. Law Commission Report No 249 Liability for Psychiatric Illness (London: HMSO, 1998).

4. Negligence (Psychiatric Illness) Bill ss 1(2), 2(2), 5(2).

5. Hinz v Berry [1970] 2 QB 40, Denning MR at 42. 


\section{Legal Studies}

psychiatric illness', as opposed to mere grief, distress or other emotion, is one that has held particular sway with the courts, having been restated on numerous occasions in both the House of Lords ${ }^{6}$ and the Court of Appeal. ${ }^{7}$ The standard test is most commonly attributed to Lord Bridge, who, in the McLoughlin case, noted:

The common law gives no damages for the emotional distress which any normal person experiences when someone he loves is killed or injured. Anxiety and depression are normal human emotions. Yet an anxiety neurosis or reactive depression may be recognisable psychiatric illnesses, with or without psychosomatic symptoms. So the first hurdle which a plaintiff claiming damages of the kind in question must surmount is to establish that he is suffering, not merely grief, distress or any other normal emotion, but a positive psychiatric illness. ${ }^{8}$

Given a plain text reading, this test may seem relatively straightforward. Indeed, the apparent logic of such a de minimis threshold has no doubt contributed to its subsequent application in criminal law as well as private law, particularly with regard to the courts' reading of the Offences Against the Person Act 1861 to include the infliction of non-physical harm. Yet in reaching his decision, Comyn J reviewed the relevant case-law extant at the time and, while conceding that orthodoxy required the presence of a recognised psychiatric condition, also identified that 'no absolutely clear picture emerges and many of the judgments speak with different voices'?

This paper will examine in detail the many and varied rationales, and subsequent problems, that have emerged in relation to the retention of this test in both private and criminal law. In particular, the focus shall be on the law's reliance on mental health science in maintaining this threshold. While the desire to defer to medical knowledge in determining the cut-off point between 'mere emotion' and 'recognisable psychiatric injury' is understandable, it will be argued that the increasingly passive position adopted by the courts belies the fundamental incompatibility between the questions of ultimate concern in the law, and the medical criteria used to make a clinical diagnosis. It will be demonstrated that this incompatibility has been exacerbated yet further by the publication of the latest edition of the diagnostic manual, the DSM-V, in 2013. To combat this, it will be suggested that law makers should engage more proactively with the mental health sciences and seriously consider the creation of diagnostic guidelines specifically for use in the legal arena. While such suggestions have previously been dismissed on the grounds of practicality, the emergence of the diagnostically weak 'battered woman syndrome' (BWS) as a relevant consideration in abused partner cases serves as an excellent example of the courts' ability to proactively engage with the mental health sciences and tailor medical knowledge to their own specific needs.

6. Alcock v CC of South Yorkshire Police [1992] 1 AC 310 (HL)422; Hicks v CC of South Yorkshire Police [1992] PIQR 433 (HL) 436; Page v Smith [1996] AC 155 (HL) 167, 171, 181, 189, 197; White (Frost) v CC of South Yorkshire Police [1999] 2 AC 455 (HL)469, 491, 501.

7. Attia v British Gas plc [1988] QB 304 (CA) 320; Hicks v CC of South Yorkshire Police [1992] 1 All ER 690 (CA) 693.

8. McLoughlin v O'Brian [1983] AC 410 at 431 (Lord Bridge).

9. Above $\mathrm{n} 1$. 


\section{PRIVATE LAW}

The courts first displayed a willingness to engage with psychological and psychiatric principles of diagnosis as they pertain to claims for psychiatric injury due to negligence. In common law, the courts' orthodox position on accepting the reality of psychiatric injury and thus permitting negligence claims for such conditions can trace its roots to the latter years of the nineteenth century in the Irish case of Bell v Great Northern Railway Co of Ireland, ${ }^{10}$ and to the turn of the twentieth century and the English case of Dulieu $v$ White \& Sons. ${ }^{11}$ In each of these cases, the courts ruled for the first time that parties in breach of a duty could be held liable in negligence for causing some form of psychiatric injury so long as the victim's condition could be shown to have derived from a reasonable fear of personal injury. In the Dulieu case, Phillimore J stated that 'terror wrongfully induced and inducing physical mischief gives a cause of action'. ${ }^{12}$ The judgments in these cases marked a significant evolution in the thinking of the courts. Previously, the orthodox position was characterised by a belief that in order for any kind of nervous shock to be recoverable, it must also have been accompanied by a concurrent physical injury. Lord Wensleydale had commented that, 'Mental pain or anxiety the law cannot value, and does not pretend to redress, when the unlawful act complained of causes that alone. ${ }^{13}$ Indeed, in 1888 the Privy Council had decided, in the Australian case of Coultas, ${ }^{14}$ that psychiatric harm caused by fear of being run over by a train was too remote a condition to warrant a successful claim.

This initial reluctance to engage with the notion of psychiatric injury without an accompanying physical injury, as characterised by Lord Wensleydale, and the Privy Council judgment in Coultas, is perhaps understandable given the paucity of psychological/psychiatric evidence available at the time. Indeed, the courts are to be praised for the alacrity with which they were willing to engage with any notion of psychiatric injury as a result of negligence given the relative infancy of research based mental health science at that time. Less praiseworthy has been the speed with which private law courts have been willing to incorporate more contemporary terminologies to describe mental health issues; for example, from a mental health perspective, the continued use of 'nervous shock' as the umbrella term to describe all psychiatric injury is of itself problematic. As Trindade has correctly noted, this is a relatively crude expression that fails to properly encapsulate the breadth of contemporary mental health science. ${ }^{15}$ While the retention of such outmoded terminology may itself be indicative of limited engagement with contemporary mental health science, as Lord Bridge stated, it is now accepted that it is possible for a claim in negligence to succeed without any physical component, provided that the symptoms exceed 'mere emotion' and amount to a recognisable psychiatric injury. In determining the cut-off point between mere emotion and 'recognisable psychiatric injury', the courts have, for the most part, adopted a passive stance and been willing to defer to mental health practitioners, and the diagnostic criteria developed by the mental health sciences designed to aid suitably trained experts to make clinical diagnoses. As Lord Steyn commented, 'Where the line is to be drawn is

10. (1890) 26 LR Ir 428.

11. [1901] 2 KB 669 .

12. Ibid, at 683 .

13. Lynch $v$ Knight [1861] 9 HLC 577 at 590 (Lord Wensleydale).

14. Victorian Railways Commissioners v Coultas (1888) 13 App CAS 222.

15. FA Trindade 'The principles governing the recovery of damages for negligently caused nervous shock' (1986) 45(3) Camb L J 476-500. 


\section{Legal Studies}

a matter for expert psychiatric evidence. ${ }^{16}$ This position is fully endorsed by the Law Commission who have stated that '... expert medical evidence will generally be required to establish that the plaintiff has suffered a recognisable psychiatric illness', ${ }^{17}$ and by some academic commentators. ${ }^{18}$

\section{CRIMINAL LAW}

In comparison, criminal courts have generally demonstrated greater willingness to engage actively with contemporary mental health science. The explanation for this is doubtless rooted in the frequent characterisation of English criminal law as an adversarial struggle between the accused/defendant and the state. ${ }^{19}$ The relative disparity in resources between a private individual charged with a crime and the various branches of the state that are responsible for conducting criminal investigations and prosecutions has received extensive judicial and academic comment. ${ }^{20}$ As a direct consequence of this 'adversarial deficit', great efforts have been taken to ensure that the rights of defendants and, indeed, the reliability and integrity of criminal proceedings - are not unduly impinged upon at either the 'evidential stage' of the criminal process ${ }^{21}$ or during the trial itself. Increasingly, mental health sciences have played an important role in maintaining this integrity with psychologists and psychiatrists being employed by the court in myriad situations. These range from participation in drafting some of the comprehensive guidelines provided for the police in the codes of practice that accompany the Police and Criminal Evidence Act (PACE) regarding the appropriate measures to be observed when interviewing vulnerable individuals, including the need for an appropriate adult (AA) to be in attendance, ${ }^{22}$ through the extensive testing of defendants to ensure that their levels of suggestibility and/or compliance are not sufficiently high to render confession evidence unreliable, ${ }^{23}$ to more general assessments of an individual's fitness to plead or stand trial. ${ }^{24}$ While the effective use of both psychology and psychiatry to help ensure that both the rights of the defendant and the reliability of the criminal process are maintained is commendable, critics have argued that this application of mental health science to 'evidential' issues belies what can only be described as a traditionally reticent view of emotional harm in the criminal law, particularly as regards victimhood. ${ }^{25}$

16. White, above n 6, at 491 (Lord Steyn).

17. Ibid, at n 3 (para 2.3).

18. See eg P Case 'Secondary iatrogenic harm: claims for psychiatric damage following a death caused by medical error' (2004) 67 Mod L Rev 561.

19. A Ashworth and R Redmayne The Criminal Process (Oxford: Oxford University Press, 4th edn, 2010).

20. Ibid; H Stacey and M Lavarch Beyond the Adversarial System (Sydney: The Federation Press, 1999).

21. M Zander The Police and Criminal Evidence Act (London: Sweet \& Maxwell, 5th edn, 2005).

22. PACE code $3 ; \mathrm{S}$ Young et al 'The effectiveness of police custody assessments in identifying suspects with intellectual disabilities and attention deficit hyperactivity disorder'. (2013) 11 BMC Med 248; B Littlechild and D Fearns 'Mentally vulnerable adults in police detention' in Mental Disorder and Criminal Justice (Lyme Regis: Russell House, 2005).

23. GH Gudjonsson The Psychology of Interrogations and Confessions: A Handbook (Chichester: Wiley, 2003).

24. $R v$ Pritchard (1836) 7 C\&P 303: The Pritchard Test.

25. E Erez 'Who's afraid of the big bad victim? Victim impact statements as victim empowerment and enhancement of justice' (1999) 49(26) Crim L Rev 545. 
The traditional position adopted by criminal courts in the UK has been one of extreme reluctance to engage with, or criminalise, behaviour that inflicts psychological harm on a victim without some accompanying physical injury. ${ }^{26}$ This prevailing focus on a tangible physical injury in criminal law closely mirrors the traditional position in tort, outlined above, which accorded a certain primacy to claims arising out of physical injury. ${ }^{27}$ This is particularly relevant as regards the Offences Against the Person Act 1861 (the 1861 Act), which sets the standard definitions for a range of non-fatal injuries. Given the era in which this statute was drafted, it is perhaps unsurprising that no specific mention is made of emotional or psychiatric injury but, rather, the focus is very much on varying degrees of 'bodily' or physical injury. In spite of this apparently narrow legislative framework, the courts have introduced a broader reading of what constitutes 'injury' in a criminal context to include psychiatric harm. This willingness to extend protection to individuals who develop a 'psychiatric illness' as a result of another's behaviour can be neatly highlighted with reference to the conjoined cases of $R v$ Ireland and $R v$ Burstow. ${ }^{28}$ First, in $R v$ Ireland, it was held that repeatedly making silent telephone calls to someone resulting in their developing a psychiatric illness can constitute actual bodily harm within the meaning given to that offence in the 1861 Act. $^{29}$ Similarly, in $R v$ Burstow, the court held that stalking someone to the point at which they develop a psychiatric illness can constitute grievous bodily harm. ${ }^{30}$ While these cases are indicative of the court's willingness to engage with the constraints imposed upon it by outdated legislation, it is crucial to note that any extension of criminal liability to include the infliction of non-physical injury must clearly still be couched within the strict tort standard of having caused a 'recognisable psychiatric illness' as opposed to mere emotion.

This point was reinforced in the Chan-Fook case by Hobhouse LJ, who commented:

The phrase 'actual bodily harm' is capable of including psychiatric injury, but it does not include mere emotions such as fear, distress or panic, nor does it include, as such, states of mind that are not in themselves evidence of some identifiable clinical condition. $^{31}$

Indeed, the court went further by declaring, per curiam, that 'state of mind' was an 'unscientific expression' and therefore unhelpful in deciding if a psychiatric injury had occurred; rather, expert evidence from a psychiatrist or psychologist would be required. ${ }^{32}$ Should such expert testimony not be introduced by the prosecution, the matter should not be left to the jury for consideration. ${ }^{33}$ This apparent willingness to defer to the scientific rigour offered by a clinical diagnosis and to rely on expert testimony from mental health professionals closely mirrors the approach adopted in private law detailed above.

26. JE Stannard 'Sticks, stones and words: emotional harm and the English criminal law' (2010) 74 J Crim L 533-556.

27. Ibid; H Teff Causing Psychiatric and Emotional Harm: Reshaping the Boundaries of Legal Liability (Oxford: Hart Publishing, 2009).

28. $R v$ Burrows, $R$ v Ireland [1998] AC 147.

29. Ibid, at 158 (Lord Steyn).

30. Ibid, at 161 (Lord Steyn).

31. $R v$ Chan-Fook (1994) 99 Cr App R 147 at 152 (Hobhouse LJ).

32. Ibid.

33. Ibid. 


\section{Legal Studies}

The key concern for both private and criminal courts therefore seems to be in establishing a cut-off point between 'mere emotions' and clinical symptoms amounting to psychiatric injury, with expert testimony playing a key role in this process. This willingness to defer to the expertise of mental health practitioners and the diagnostic criteria that they use no doubt seems logical, particularly in light of the commonly held misconception that there exists a "considerable degree of international agreement on the classification of mental disorders and their diagnostic criteria' ${ }^{34}$ While it may be true that on those occasions when experts are in agreement their testimony can be of significant value to the courts, ${ }^{35}$ as shall be seen, disagreements when they arise can lead to confusion and uncertainty.

\section{DIAGNOSTIC DISAGREEMENTS}

In private law, the propensity for practitioners to reach different conclusions is neatly evidenced in the Scottish case of Dickie v Flexcon Glenrothes Ltd. ${ }^{36}$ In that case, three different psychiatrists each came to different conclusions as to both the severity of the condition suffered by the plaintiff and the very nature of the condition itself. One expert returned a diagnosis of a moderate depressive episode which was subsequently changed to a diagnosis of dysthymia; the second witness diagnosed a depressive disorder; and the final expert diagnosed an adjustment disorder. Furthermore, it was reported in the case that one of the experts was dismissive of the value of the diagnostic criteria themselves, having preferred to rely on his own clinical judgment, and that yet another was dismissive of the evidence provided by one of his colleagues, noting that the terminology used was old-fashioned. ${ }^{37}$

Similar disagreements between expert witnesses can readily be found in a criminal context; the case of Dhaliwal ${ }^{38}$ provides a particularly harrowing example of this. In that case, the defendant was charged with causing grievous bodily harm contrary to s 20 of the 1861 Act, and manslaughter following the suicide of his wife. In support of these charges, evidence was adduced that showed the defendant had subjected his wife to sustained abuse which, while mostly psychological in nature, had also included clear incidents of physical assault. ${ }^{39}$ In spite of the clear evidence to suggest that this man's conduct had led directly to his wife's suicide, he was acquitted on both counts. The reasons for this acquittal were twofold. First, although there had clearly been instances of physical assault, the prosecution were unable to establish a direct causal link between these assaults and the victim's suicide. ${ }^{40}$ Had they been able to establish such a direct causal link between the physical assaults endured by the victim and her death, the prosecution case would have been relatively straightforward, but instead the focus shifted on to the second issue; the exact nature of the psychological harm experienced by the victim. In keeping with the direction in Chan-Fook, in attempting to establish the severity of the victim's

34. Sutherland $v$ Hatton [2002] 2 All ER 1 at 5 (Hale LJ).

35. Monk v PC Harrington Ltd [2008] EWHC 1879 (QB).

36. Dickie v Flexcon Glenrothes Ltd [2009] Scot (D) 3/11 (Sheriff Court, Kircaldy, 4 September 2009).

37. Ibid, at 22 (Sheriff Braid).

38. $R v$ Dhaliwal [2006] EWCA Crim 1139.

39. Ibid, at 3 .

40. Ibid, at 8 . 
condition at the time of her death, the prosecution commissioned expert reports from no less than three independent mental health professionals; one clinical psychologist with expertise in cases involving abused partners, Dr Roxanne Agnew-Davies, and two distinguished consultant psychiatrists, Dr Gillian Mezey and Dr LP Chesterman. ${ }^{41}$

It should be noted that in coming to their conclusions, none of these experts had the opportunity to meet and formally assess the victim. Instead, they were provided with personal diaries of the deceased and had access to evidence gathered by the police. While all of the experts agreed that the victim had clearly been subjected to a great deal of emotional and physical abuse, only Dr Mezey concluded that there was sufficient evidence to diagnose a recognised psychiatric illness, specifically clinical depression. ${ }^{42} \mathrm{Dr} \mathrm{Ag}$ new-Davies acknowledged that the victim's ordeal had led to the presence of several symptoms of depression and PTSD, but could not be satisfied without formal assessment that these symptoms reached the required standard for a clinical diagnosis. Similarly, while Dr Chesterman had no hesitation in concluding that the victim's psychological functioning had clearly been impaired by sustained abuse, noting that '[The] psychological impact of the assault perpetrated by her husband on the day of her suicide is likely to have been greatly magnified by the number of such experiences over many years', ${ }^{43}$ he was unable to confirm that this psychological impairment had resulted in a recognised psychiatric illness.

As a consequence of this inconsistency between the experts reports produced, the prosecution were forced to concede that there was no recognised psychiatric illness and to proceed with the case on the basis that the psychological impairment suffered by the victim was sufficient to constitute bodily injury. ${ }^{44}$ This proposition was rejected by both the trial judge and on appeal, with the appeal court restating the orthodox position that only a recognisable psychiatric illness could constitute bodily harm.

\section{Dimensional answers to categorical questions}

In trying to explain why such disagreements occur, it is necessary to examine how mental health practitioners reach diagnoses. The diagnostic criteria used by mental health practitioners to determine the presence and extent of any psychiatric illness are contained within two separate systems, the ICD 10, published by the World Health Organization, ${ }^{45}$ and the DSM-V,${ }^{46}$ published by the American Psychiatric Association. ${ }^{47}$ Despite its traditional reputation for reliability, ${ }^{48}$ the capacity for disagreement between practitioners, particularly within the finite timescale available for assessment in legal proceedings, is arguably unavoidable given the formulation of the DSM. ${ }^{49}$ While it is

41. Ibid, at 13 .

42. Ibid, at 14 .

43. Ibid, at 15 .

44. Ibid, at 18 .

45. The consultation process preceding the release of the ICD-11 is currently ongoing.

46. DSM-V The Diagnostic and Statistical Manual of Mental Disorders (Washington, DC: American Psychiatric Association, 5th edn, 2013).

47. For the purposes of this paper, greater emphasis will be place on the role of the DSM as it focuses solely on mental health diagnoses. The ICD 10 is a general classification of all diagnosable conditions, with those pertaining to mental health being contained in ch 5 .

48. R Mayes and A Horowitz 'DSM-III and the revolution in the classification of mental illness' (2005) 41(3) J Hist Behav Sci 249.

49. H Kennedy 'Limits of psychiatric evidence in civil courts and tribunals: science and sensibility' (2004) 10 Med-L J Ireland 16 at 18. 


\section{Legal Studies}

of course preferable, for the purposes of reliability, that two different clinicians viewing the same patient should come to the same clinical diagnosis, the checklist approach exemplified by diagnostic manuals does not, on a plain text reading, allow for full consideration of the contextual information and clinical experience that each practitioner may use in making his or her final assessment. ${ }^{50}$ Any disagreements that emerge in the ordinary course of clinical practice can usually be resolved by additional, more detailed assessments, a luxury not often afforded by the courts. ${ }^{51}$

This issue serves to highlight the crucial point that these criteria were not developed specifically for use in a legal environment, which places a substantially different emphasis on the criteria than that which is applied in a purely clinical setting. From a clinical perspective, reliability in a diagnosis is important in facilitating appropriate treatment, yet in a legal context, the courts are simply concerned with whether or not the symptoms experienced by the claimant reach the de minimis threshold of recognisable psychiatric injury. ${ }^{52}$ In other words, the courts are seeking a categorical 'yes' or 'no' answer as to the presence of a recognised condition. However, while the conditions listed in the DSM may appear categorical, they are in fact frequently dimensional, being composed of a series of clinically important symptoms that in practice occur in varying levels of severity, and which in turn may be relevant to multiple different diagnoses. ${ }^{53}$ This adds greatly to the difficulty inherent in coming to a final diagnosis.

This fundamental difference in approach has led to much difficulty in satisfactorily applying the diagnostic criteria in a legal context. ${ }^{54}$ It is perhaps for this reason that in several instances judges have been willing to extend leeway to expert witnesses regarding the extent to which they frame their testimony within the language of the diagnostic criteria. Morland $\mathrm{J}$ in particular has commented that these strict categorisations are of limited value, noting that the persuasiveness of the testimony, rather than the specific label used to describe the condition in question, is what matters to the court. ${ }^{55} \mathrm{~A}$ similar attitude has been expressed in the Irish case of Murtagh v MOD, ${ }^{56}$ where the court makes specific reference to the 'wealth of experience' and 'clinical diagnostic expertise' of the witness being of greater importance than 'formulaic categorisations'. Other judgments have also dammed the diagnostic criteria with faint praise by describing them as 'a useful guide', ${ }^{57}$ but 'not necessarily conclusive'. ${ }^{58}$ Such an approach to expert witnesses presents a real danger that it is the persuasiveness of the expert rather than the severity of the symptoms that may ultimately decide the outcome of a case.

\section{The judge as mental health expert}

Perhaps more troublingly, from the perspective of the mental health practitioner, there are also several examples of the court making its own interpretation of the diagnostic criteria

50. D Gill 'Proving and disproving psychiatric injury’ (2008) 78 Med-L J 143.

51. Kennedy, above $\mathrm{n} 49$.

52. Noble v Owens [2008] EWHC 359 (QB).

53. DA Grayson 'Can categorical and dimensional views of psychiatric illness be distinguished?' (1987) $151 \mathrm{Br} J$ Psych 355.

54. Dickie, above $\mathrm{n}$ 36, at 33 (Sheriff Braid). An excellent example of this can be seen in Sheriff Braid's summary of the submissions pertinent to the Dickie case and the conclusion that '.. the diagnosis of psychiatric illness in not an exact science!'

55. Group B Plaintiffs v UKMRC [2000] Lloyd's Rep Med 161 (QB) at 113 (Moorland J).

56. [2008] IEHC at 292.

57. Gardner v Epirotiki Steamship Co (QBD, 7 June 1994) Wright J.

58. Rorrison $v$ West Lothian College [2000] SCLR 245 Lord Reed. 
without the aid of trained mental health experts, an approach no doubt facilitated by the checklist appearance of these criteria in the diagnostic manuals, ${ }^{59}$ and the difficulty in securing consistent expert testimony. In both England ${ }^{60}$ and Australia, ${ }^{61}$ courts have applied what Brigg $\mathrm{J}$ has termed a 'common sense application of the DSM-IV criteria', ${ }^{6}$ in determining if the symptoms required for a diagnosis of pathological gambling were present. Similarly, with regard to the veracity of a claim based upon the presence of PTSD, Evans LJ seemed dismissive of the need for expert testimony, at least initially, preferring instead an examination of the 'factual evidence' about the claimant's behaviour based on his own interpretation of the symptoms listed in the diagnostic manual. ${ }^{63}$ The temptation for the court to indulge in this kind of analysis is perhaps understandable, given both the propensity for practitioners to disagree about a diagnosis and the checklist presentation of symptoms in the DSM that may, on an initial inspection, seem self-explanatory to even the most clinically inexperienced reader; nevertheless, judicial restraint should be employed as far as is practical.

As has been discussed, the checklist appearance of symptoms belies the requisite underlying clinical expertise and judgment required to fully diagnose a condition. Furthermore, as Gill noted, a more detailed reading of both the DSM and the ICD diagnostic manuals reveals a series of subtle caveats that accompany the more clearly stated list of symptoms, and that these caveats must be fully considered before arriving at any reliable diagnosis; yet this process is frequently overlooked in the legal arena. ${ }^{64}$ Indeed, the DSM itself contains a specific warning about the dangers inherent in an interpretation of symptoms without the requisite clinical expertise:

When DSM categories, criteria, and textual descriptions are employed for forensic purposes, there is a risk that diagnostic information will be misused or misunderstood. These dangers arise because of the imperfect fit between the questions of ultimate concern to the law and the information contained in a clinical diagnosis. ${ }^{65}$

\section{The importance of policy considerations}

In spite of these fundamental concerns surrounding the utility of these diagnostic standards in a legal setting, their continued use has received additional judicial support after Burnton $\mathrm{LJ}$ restated the importance of the diagnostic criteria in establishing the presence of a recognisable psychiatric illness. ${ }^{66}$ That this standard is being so jealously guarded in spite of the concerns raised speaks volumes for its utility in providing a method for judicial control. ${ }^{67}$ When viewed through the prism of private law, as Comyn J previously noted, ${ }^{68}$ certainty as to the rationale underlying the courts' desire to exercise such control has at times been far from clear. One possible explanation for the ongoing use of 'recognisable psychiatric injury' as the orthodox standard for a successful claim, in spite of the difficulty

59. Gill, above $\mathrm{n} 50$.

60. Calvert v William Hill Credit Ltd [2008] EWHC 454.

61. Foroughi v Star City Pty Ltd [2007] FCA 1503.

62. Calvert, above n 60, at 134 (Brigg J).

63. Vernon v Bosley (No 1) [1997] 1 All ER 577 (CA) at 598 (Evans LJ).

64. Gill, above $\mathrm{n} 50$.

65. DSM-V, above n 46, p 25.

66. Hussain v CC of West Mercia Constabulary [2003] EWCA Civ 1205.

67. See Group B Plaintiffs v UKMRC [2000] Lloyd's Rep Med 161 (QB), Moorland J at 163 describing it as a 'powerful control mechanism'.

68. Above $\mathrm{n} 1$. 
inherent in applying the medical knowledge, is offered by Lord Justice Evans, who commented that "in technical legal terms, damages for "normal" grief and suffering may be said to be too remote to be recoverable in law' ${ }^{69}$ Yet academic commentary ${ }^{70}$ and alternative judicial opinion ${ }^{71}$ would seem to refute this suggestion, instead noting that policy concerns rather than legal principles underlie the courts' attachment to such a high orthodox standard; indeed, as seems clear, retention of such a standard has been for 'reasons more to do with policy than logic'. ${ }^{72}$ As Giliker ${ }^{73}$ has observed, these policy concerns can seemingly be overcome in certain situations, as damages for the infliction of mental distress falling below the threshold of recognisable psychiatric injury have been awarded in the form of aggravated damages, provided that there is an accompanying physical injury. Additionally, supplementary damages for mental distress may accompany ordinary compensation in the case of intentionally inflicted torts, or torts that are actionable per se. Crucially, this apparent recognition of more minor symptoms occurs in a subtle, almost secretive fashion, with the courts remaining unwilling to openly acknowledge this as a head of damages. In particular, there has been a refusal to consider any such award in relation to negligence cases where policy objections have remained insurmountable.

Chief among these policy concerns ${ }^{\uparrow 4}$ is a desire to control the number of possible claimants, so as to limit the financial liability that may be incurred by the state, private insurance companies or private individuals, as such resources are "finite'. ${ }^{75}$ As Lord Wilberforce noted, mental injury is 'capable of affecting so wide a range of people, [there is] a real need for the law to place some limitation on the extent of admissible claims'. ${ }^{76}$ Yet the sheer number of limiting mechanisms developed by UK courts has received extensive criticism. ${ }^{77}$ Rather than operating as occasional limiting factors, policy considerations have come to dominate any discussion on psychiatric injury claims. In particular, the troublesome contemporary position in UK private law that differentiates between primary and secondary victims serves as an excellent example of the primacy afforded to policy considerations in English private law, with the controls applied to secondary victims being a topic of considerable academic ${ }^{78}$ and judicial debate. ${ }^{79}$ The development and retention of these policy controls has seen the UK diverge widely from other common law jurisdictions such as Australia where, in summarising the position of the law in the $\mathrm{UK}$, Gummow $\mathrm{J}$ observed that the policy controls were being operated in an 'arbitrary' and 'capricious' manner, further noting that such unprincipled distinctions 'bring the law into disrepute'. ${ }^{80}$

69. Vernon, above n 63, at 604 (Evans LJ).

70. R Mulheron 'Rewriting the requirement for a "recognised psychiatric injury" in negligence claims' (2012) 32(1) Oxford J Legal Stud 77-112.

71. Alcock v CC of South Yorkshire Police [1992] 1 AC 310 (HL) 422 at 418 (Lord Oliver).

72. White $v$ London Fire \& Civil Defence Authority [1999] 2 AC 410 at 511 (Lord Hoffman).

73. P Giliker "A "new" head of damages: damages for mental distress in the English law of torts' (2000) 20(1) Legal Stud 11-41.

74. Although certainly not the only such concern. For a comprehensive review, see Teff, above n 27, pp 141-170.

75. Sion v Hampstead HA [1994] 5 Med LR 170 (CA) at 173 (Staughton LJ).

76. McLoughlin, above $\mathrm{n} 8$, at 421 (Lord Wilberforce).

77. K Patten 'Patchwork quilt law' (2013) New L J, 24 May.

78. Ibid; Mulheron, above $\mathrm{n} 70$; P Handford 'Psychiatric Injury in breach of a relationship' (2007) 27(1) Legal Stud 26-50.

79. See White, above n 6, at 496-498 (Lord Steyn) and at 504 (Lord Hoffmann).

80. Tame v New South Wales, Annetts v Australian Stations Pty Ltd (2002) 191 ALR 449 at 494 (Gummow JJ). 
Given that the development and maintenance of such seemingly controversial and arbitrary restrictions has become one of the central preoccupations of civil courts in the UK, particularly following the Hillsborough disaster, a more cynical view should perhaps be taken of the Law Commission and the judiciary's insistence that the diagnostic criteria and the orthodox standard of 'recognisable psychiatric illness' be retained in spite of the obvious problems in application detailed above. Rather than being based on a genuine misunderstanding as to the strengths and weaknesses of the diagnostic process, retention of this standard seems to offer some additional arbitrary measure of imagined diagnostic or scientific justification for financially driven policy decisions. It is important to note that the purpose of highlighting this point is not to add further criticism to the courts' retention of policy controls in general. Rather, it is to emphasise that such policy concerns should be entirely divorced from any discussion as to the efficacy of retaining 'recognisable psychiatric injury' as the de minimis threshold for a successful claim in negligence. Indeed, by allowing the diagnostic criteria to be used as such an additional means of judicial control law makers in the UK have left themselves at the mercy of ongoing developments in mental health sciences.

\section{DEVELOPMENTS IN MENTAL HEALTH SCIENCE}

As has been examined earlier, to suggest that there is 'considerable international agreement ${ }^{81}$ is demonstrably false in terms of the number of divergent opinions that may manifest between different, equally well-trained and experienced practitioners regarding a single diagnosis. Crucially, the same may be said in terms of the levels of support within the mental health professions for the criteria set out in the DSM generally. A key concern has emerged regarding the presence of diagnostic inflation, which has seen a dramatic increase in the numbers of individuals receiving a psychiatric diagnosis. ${ }^{82}$ The publication of the new DSM-V in 2013 has subsequently received extensive criticism from within the ranks of mental health professionals; including high-profile concerns raised by Robert Spitzer $^{83}$ and Allen Frances, ${ }^{84}$ the chairmen of the DSM-III and DSM-IV taskforces, respectively, regarding its likely impact on such diagnostic inflation. Of central concern is the new appearance of the criteria, which have departed from the relatively strict categorisations contained in the DSM-IV and are now more broadly conceived, including new categories and lower diagnostic thresholds:

DSM-5 seems likely to convert diagnostic inflation into diagnostic hyperinflation by adding new, questionable, and untested diagnoses, and by reducing the thresholds for

81. Sutherland, above $\mathrm{n} 34$, at 5 (Hale LJ).

82. RC Kessler et al 'Prevalence, severity, and comorbidity of 12-month DSM-IV disorders in the National Comorbidity Survey Replication' (2005) 62(6) Arch Gen Psych 617-627 [published correction appears in (2005) 62(7) Arch Gen Psych 709]; RC Kessler et al 'Lifetime prevalence and age-of-onset distributions of DSM-IV disorders in the National Comorbidity Survey Replication' (2005) 62(6) Arch Gen Psych 593-602 [published correction appears in (2005) 62(7) Arch Gen Psych 768].

83. B Carey 'Psychiatrists revise the book of human troubles' New York Times 17 December 2008, available at http://www.nytimes.com/2008/12/18/health/18psych.html?pagewanted=all (accessed 15 January 2015).

84. 'Psychiatrists propose revision to diagnostic manual' (Interview for PBS NewsHour 10 February 2010), available at http://www.pbs.org/newshour/bb/health-jan-june10-mentalillness_ 02-10/ (accessed 15 January 2015). 
existing diagnoses. Normal grief may be mislabeled as major depressive disorder, temper tantrums become disruptive mood dysregulation disorder, normal forgetfulness in old age is now mild neurocognitive disorder, overeating is binge-eating disorder, and poor concentration is adult attention-deficit/hyperactivity disorder. ${ }^{85}$

These criticisms have been underlined by a perceived lack of transparency during the consultation process leading up to publication, sparking fears that the pharmaceutical industry was exerting undue influence to ensure that diagnostic criteria were lowered so as to profit from the subsequent rise in diagnoses requiring medication. ${ }^{86}$ Similar concerns have been raised by a number of psychological and psychiatric associations, including the British Psychological Society which, in an open letter in 2011 stated:

The Society is concerned that clients and the general public are negatively affected by the continued and continuous medicalisation of their natural and normal responses to their experiences; responses which undoubtedly have distressing consequences which demand helping responses, but which do not reflect illnesses so much as normal individual variation.

Regardless of whether the courts' purported adherence to the diagnostic criteria is fuelled by a genuine desire to defer to mental health experts, or a need to provide justification for policy-based decisions, the possible lowering of the diagnostic threshold leading to the 'medicalisation' of 'natural' and 'normal' responses has the potential to dramatically increase the number of claimants who reach the required standard of 'recognisable psychiatric illness'. While it is too early in the life of the DSM-V to reach any firm conclusion as to the merits of such concerns, the mere suggestion that the diagnostic thresholds have been lowered must be of concern to the courts.

In response to these criticisms, advocates in favour of the new system, including David Kupfer, the chair of the DSM-V taskforce, while acknowledging the relative breadth of the new categories when compared with the DSM-IV, have refuted the suggestion that diagnostic thresholds have been substantially lowered. ${ }^{87}$ Rather, it is suggested that the DSM-V has a broader construction to ensure sensitivity to as many symptoms and conditions as possible, but that the more explicit emphasis on the dimensional assessment of the severity of symptoms contained within the manual will act as an inbuilt check against diagnostic inflation. ${ }^{88}$ As mentioned above, Grayson ${ }^{89}$ has already observed that such a dimensional examination of symptoms already played an important role in reaching a diagnosis; however, as Gill noted, ${ }^{90}$ the inclusion of such additional measures in the DSM-IV was relatively subtle. In contrast, the DSM-V explicitly includes a series of severity measures that are to be applied before a diagnosis can be confirmed and appropriate intervention planned.

85. A Frances and M Raven 'Two views of the new DSM-5: the need for caution in diagnosing and treating mental disorders' (2013) 88(8) Am Fam Physician, available at http://www.aafp.org/ afp/2013/1015/od1.html (accessed 17 July 2015).

86. A Frances 'A warning sign on the road to DSM-V: beware of its unintended consequences' Psychiatric Times 26 June 2009, available at http://www.psychiatrictimes.com/articles/warningsign-road-dsm-v-beware-its-unintended-consequences?verify=0A (accessed 15 January 2015).

87. DJ Kupfer, EA Kuhl and DA Regier 'Two views of the new DSM-5: a diagnostic guide relevant to both primary care and psychiatric practice' (2013) 88(8) Am Fam Physician, available at http://www.aafp.org/afp/2013/1015/od2.html (accessed 17 July 2015).

88. Ibid.

89. Grayson, above $\mathrm{n} 53$.

90. Gill, above n 50 . 
While this attempt to more openly consider the dimensional component of conditions may indeed serve to address concerns about diagnostic inflation, it is difficult to see how such a change can have anything other than a negative impact on the utility of the diagnostic manual in a legal context. The reasons for this are twofold. First, as has already been discussed, the dimensional component of a diagnosis has always been problematic for the courts, given their preference for a strictly categorical answer as to the presence of any condition. That this dimensional component is now set to play such an important role can only serve to accentuate this problem. The second issue of concern relates to the time required to complete a diagnosis. As previously discussed, experts who have been asked to reach a diagnosis for legal proceedings must operate within a finite timescale, but both the critics and supporters of the DSM-V are in agreement that individual practitioners should take a more longitudinal view of diagnoses, with greater care being taken before a diagnosis is confirmed and medication prescribed. ${ }^{91}$ This call for a more longitudinal approach must surely clash with the time constraints inherent in legal proceedings and place yet further pressure on expert witnesses. As mentioned above, this is of particular concern as attempting to expedite the diagnostic process for legal proceedings has been a contributing factor in contradictory testimony from different experts, which has in turn produced confusion and uncertainty.

Thus, even if the concerns raised about the lowering of the diagnostic thresholds prove to be unfounded, the publication of the DSM-V seems set to accentuate the existing difficulties inherent in applying diagnostic material in a legal environment. Such developments within the mental health professions must surely undermine the extent to which the court can, with confidence, rely on the diagnostic criteria - and, indeed, increasingly contradictory expert testimony - while simultaneously attempting to both limit the numbers of potential claimants and maintain the integrity of legal proceedings.

\section{Policy concerns in the criminal law}

Since criminal law has borrowed so heavily from private law with regard to psychiatric injury and the need for expert testimony, these developments in the mental health sciences must necessarily be a cause for concern. Yet the impact of such changes to the diagnostic process is more difficult to gauge in respect of criminal law, as the underlying rationale for the retention of such a high de minimis threshold in relation to the 1861 Act is less clear. The most persuasive policy argument offered to explain the reluctance of UK courts, to extend criminal liability under the Offences Against the Person Act to cases of 'mere emotion', is rooted in the same basic floodgates argument that applies in private law. ${ }^{92}$ When applied in the context of criminal law, this argument manifests as an awareness of the stigma attached to a criminal conviction, and the severity of the possible sanctions to be enforced against a guilty party. This is particularly relevant given the propensity of everyday human interaction to provoke emotional responses of one kind or another; as Teff stated, 'Since much everyday conduct can have adverse emotional effects on others, imposing penal sanctions too readily could inhibit socially defensible behaviour. ${ }^{93}$

91. Frances and Raven, above n 86; Kupfer et al, above n 87.

92. Stannard, above $\mathrm{n} 26$.

93. Teff, above n 27, p 31 . 
Given this analysis, it would seem that fears regarding the lowering of diagnostic thresholds, should they prove founded, could have a dramatic impact on the number of cases that reach the de minimis standard, thus confounding any attempt to limit criminal liability. However, while the desire to limit the unnecessary imposition of penal sanctions is undoubtedly within the contemplation of the courts, there is less evidence to suggest that the 'recognisable psychiatric injury' test that necessitates reliance on the diagnostic criteria has been retained solely to facilitate this policy concern. Rather, it would seem that in some instances attempts have already been made to develop a more inclusive approach to mental harm suffered by victims of specific crimes. In $R v$ Brewster, ${ }^{94}$ Lord Bingham, the Lord Chief Justice of England and Wales at the time, extolled the virtue of such an approach in relation to burglary by making specific reference to the psychological impact that such a crime has on individuals whose home has been broken into, ${ }^{95}$ and encouraged judges to acknowledge this impact when considering sentencing. ${ }^{96}$ Perhaps more significantly, the Protection from Harassment Act 1997 already penalises behaviour that causes alarm or distress, both mere emotions. Originally conceived as a legislative response to stalkers, ${ }^{97}$ this Act has received a broad interpretation that covers all forms of harassment. ${ }^{98}$ While some commentators have suggested that the courts' reading of the Act may result in it being of little use in domestic settings such as Dhaliwal, ${ }^{99}$ there can be little doubt that this legislation gives the court a broader framework within which to consider criminal sanctions for the infliction of more minor psychological harm.

In light of this apparent weakness in the floodgates argument, a more persuasive explanation for the retention of the de minimis standard may be rooted in the ongoing use of legislation from the middle part of the nineteenth century as the framework within which all non-fatal injuries must be conceptualised. Lord Steyn has acknowledged the difficulty inherent in devising a contemporary understanding of non-physical injury within the current framework, noting that 'The proposition that a Victorian Legislator when enacting section 18, 20 and 47 of the Act 1861, would not have had in mind psychiatric illness is no doubt correct. Psychiatry was in its infancy in $1861 .{ }^{, 100}$ This incompatibility between this legislative framework dealing with offences against the person and contemporary notions of non-physical injury has not gone unnoticed, and several recommendations have been made suggesting reform of the law in this area to be more inclusive of mental health issues and non-physical harm. The Law Commission has made several such recommendations, including the use of more contemporary language that would be more nuanced and inclusive of broader definitions of harm and victimhood, specifically in relation to non-physical harm. ${ }^{101}$ Subsequently, the Home Office has explored wide-ranging reform of the legislation relating to non-fatal injury by consulting about a possible Offences Against the Person Bill that would include a wider definition of 'injury' to include 'any impairment of an individual's mental

94. $R v$ Brewster [1998] $1 \mathrm{Cr}$ App $\mathrm{R} 220$.

95. See M Maguire and T Bennett Burglary in a Dwelling (London: Heinemann, 1982).

96. $R v$ Brewster, above $\mathrm{n} 95$, at 225-227 (Lord Bingham).

97. N Addison and T Lawson-Cruttenden Harassment Law and Practice (London: Blackstone Press, 1997).

98. 'DPP $v$ Selvanayagam' The Times 23 June 1999 (Collins J).

99. Stannard, above $\mathrm{n} 26$.

100. $R v$ Burrows, $R$ v Ireland [1998] AC 147 (Lord Steyn).

101. Law Commission Report No 218 Legislating the Criminal Code: Offences Against the Person and General Principles (London: HMSO, 1993). 
health'. ${ }^{102}$ While the adoption of such a contemporary Bill would undoubtedly have provided the courts a broader framework within which to consider issues pertaining to non-physical injury, as of yet these proposed reforms have not been implemented. In the absence of a more contemporary framework within which to define non-physical harm, it is difficult to imagine how the courts could include more minor symptoms without stretching the meaning of the 1861 Act past the point of credulity.

An alternative justification for retaining recognisable psychiatric injury as the de minimis standard in relation to the 1861 Act was offered by Sir Igor Judge who, in the Dhaliwal case, focused on the need for certainty, by commenting that allowing contemplation of more minor symptoms would lead to 'problems of conflicting medical opinion'. ${ }^{103}$ Yet, as has been discussed, such problems already exist in numerous cases, including Dhaliwal. Indeed, this argument would seem to reaffirm the mistaken judicial belief that mental health practitioners apply a simple 'yes' or 'no' test of severity in reaching a clinical diagnosis. While this argument fails to fully explain retention of the de minimis standard in relation to the 1861 Act, it does highlight the importance attached to certainty in legal proceedings and recognition of how damaging conflicting medical opinion can be. Crucially, it is here that the changes in the diagnostic process caused by the publication of the DSM-V are likely to have the most damaging impact on both criminal and private law. As has been discussed, the dimensional element of a diagnosis, which has always proved to be a difficult consideration for the courts, seems set to become an even more important factor for mental health practitioners following the publication of the new diagnostic manual. This change, when coupled with the already imperfect application of medical knowledge within the legal environment, is likely to produce greater levels of disagreement between experts, adding yet further confusion and uncertainty.

\section{The case for reform}

In light of these concerns regarding the fundamental compatibility between the diagnostic criteria and the legal setting in which they are being asked to operate, several academic commentators have questioned the wisdom of their continued influence in the courtroom. To circumvent this problem, it has been suggested that in the context of private law, the basic standard of 'recognisable psychiatric illness', which necessitates reliance on diagnostic criteria, should be lowered, and that instead the court should seek to determine if the claimant has developed a psychological condition 'sufficiently different' from normal human emotions. ${ }^{104}$ In advancing this argument, Mulheron has highlighted many of the issues pertaining to interpretation and compatibility discussed above and has drawn on a growing body of judicial opinion that would seem to suggest support for lowering the threshold for a successful negligence claim. ${ }^{105}$ Similar calls for a lowering of diagnostic thresholds have also been made in the context of criminal law, particularly from commentators who, notwithstanding the broad scope of the Protection from Harassment Act, have highlighted the perceived deference with which the criminal process views the rights of the defendant, and they have contrasted it with the

102. Home Office Violence: Reforming the Offences Against the Person Act 1861 (London: Home Office, 1998).

103. $R v$ Dhaliwal [2006] EWCA Crim 1139 at 33 (Judge).

104. T Ward 'Psychiatric evidence and judicial fact finding' (1999) 3 Int J Evidence 180 at 187.

105. Mulheron, above $\mathrm{n} 70$. 
relative insensitivity that has characterised the traditional approach to victims. ${ }^{106}$ They have argued that while concerns as to the danger of criminalising everyday behaviours and interactions are certainly relevant, so too should be a more complete and inclusive awareness of the emotional cost borne by victims of non-physical injury. ${ }^{107}$

On initial inspection, the composition of the DSM-V, with broader categorisations of conditions, may seem to help facilitate such a change without the need for reform. However, the previous calls for a lowering of the diagnostic threshold were predicated on the assumption that any such change should be achieved and managed by the courts, so as to ensure easier application of medical knowledge within the legal framework. While reliance on the diagnostic criteria in the DSM-V may achieve the desired lower threshold, for the reasons outlined above, it is highly unlikely to facilitate greater compatibility. In point of fact, the central importance of dimensional assessments seems likely to foster even greater interpretative difficulties. This problem is likely to be greatly magnified if law makers adopt a passive stance and refuse to engage with these issues.

An alternative solution that would encourage more proactive engagement was suggested in Australia, where the Ipp committee, while failing to recommend a reduction in the 'recognised psychiatric illness' threshold, was highly sceptical regarding the continued usefulness of the diagnostic criteria contained in both the ICD-10 and the DSM for legal proceedings, going so far as to recommend their replacement with a different set of guidelines drawn up specifically for legal purposes in conjunction with mental health experts. ${ }^{108}$ The advantage of such an approach is that it would permit the courts to exercise greater control with regard to the issues of central importance to mental health diagnoses from a legal standpoint, while simultaneously assisting expert witnesses to better understand which particular elements of a clinical diagnosis are relevant to the courts. In the UK, such suggestions have previously been considered and rejected by the Law Commission on grounds of practicality, ${ }^{109}$ further noting the continued importance of the diagnostic criteria contained in these manuals to the psychiatric profession. ${ }^{110}$

Yet there is evidence to suggest that in certain circumstances the courts have already been willing to engage directly with mental health issues to devise diagnostic guidelines. The emergence of battered woman syndrome (BWS) as a relevant consideration in cases where abused partners retaliate is an excellent example of this. BWS and other associated symptoms have played a pivotal role in a series of successful appeals; ${ }^{111}$ and its influence can be readily identified when examining the defence of loss of control, ${ }^{112}$ which has replaced the old defence of provocation. First outlined by Walker, a psychologist, in the 1970s, and substantially revised in $1992^{113}$ and $2006,{ }^{114}$ BWS attempts to

106. J Doak 'The victim and the criminal process: an analysis of recent trends in regional and international tribunals' (2002) 23 Legal Stud 1.

107. Stannard, above $\mathrm{n} 26$.

108. 'Mental harm' in 'Review of the law of negligence: final report' (2002) ('Ipp report') as yet unenacted.

109. Law Commission Report No 249, above n 3, para 5.1.

110. Ibid, para 3.2.

111. $R$ v Ahluwalia [1993] $96 \mathrm{Cr}$ App $\mathrm{R}$ 133; $R$ v Thornton [1995] $1 \mathrm{Cr}$ App $\mathrm{R} 578$.

112. The Coroners and Justice Act 2009.

113. LE Walker 'Battered women syndrome and self-defense' (1992) 6(2) Notre Dame J L Ethics \& Pub Pol'y 321-334.

114. LE Walker 'Battered woman syndrome: empirical findings' (2006) 1087 Annals NY Acad Sci $142-157$. 
explain and categorise the experiences common to women who had experienced spousal abuse. Advocates of this syndrome have suggested that women who are exposed to sustained violence become dissociated, exhibiting signs of depression, helplessness and hopelessness that serve to restrict their capacity to leave abusive relationships. ${ }^{115}$ As Schuller and Hastings contend, the emergence of BWS as a relevant consideration can doubtless be explained by the apparent legitimacy of such a diagnosis. ${ }^{116}$ Yet several flaws in methodology and scientific validation exist relating to this syndrome in each of its incarnations, most notable among which is the fact that it is not classified in any version of the DSM. ${ }^{117}$

BWS was originally conceptualised as 'learned helplessness', in an attempt to explain the passivity of abused women and their apparent inability to leave their relationships. ${ }^{118}$ Yet this characterisation has been refuted by empirical evidence that suggests that passivity may actually be a response designed by abused women to minimise violence. ${ }^{119}$ Early versions of BWS also focused on the behaviour of the abuser, describing a cycle of violence including 'tension building', 'acute battering' and 'contrite loving' ${ }^{120}$ However, empirical evidence in support of the cycle of violence is hard to come by, and as one commentator noted, the evidence that does exist is not entirely convincing. ${ }^{121}$ Subsequent definitions of BWS were intentionally revised to be synonymous with post-traumatic stress disorder (PTSD), ${ }^{122}$ a condition that is listed in the DSM and that has been empirically linked to cases of relationship violence. ${ }^{123}$ Yet, as Dutton has noted, empirical support for PTSD should not be confused for empirical support for BWS, as "there is no "type" of PTSD called BWS'. 124

In spite of the relatively weak methodological rigour that has been employed in devising BWS, even its most ardent critics would concede that it has done much to highlight the plight of abused partners, and has helped to focus the attention of mental health researchers on the symptoms that may manifest in individuals who have experienced psychological and physical abuse. ${ }^{125}$ Evidence now suggests that while symptoms of this kind may be common in individuals who have sustained such abuse, they will be experienced differently by each individual ${ }^{126}$ and at times may not present as

115. LE Walker 'Battered women and learned helplessness' (1977) 2(3-4) Victimology $525-534$.

116. RA Schuller and PA Hastings 'Trials of battered women who kill: the impact of alternative forms of expert evidence' (1996) 20(2) Law \& Hum Behav 167-187.

117. M Dutton 'Update of the "Battered Woman Syndrome" critique' (2009) VAWnet: The National Online Resource Center on Violence Against Women, available at http://www.vawnet. org/summary.php?doc_id=2061\&find_type=web_desc_AR (accessed 15 January 2015).

118. Walker, above $\mathrm{n} 115$.

119. C Peterson, SF Maier and MEP Seligman Learned Helplessness: A Theory for the Age of Personal Control (New York: Oxford University Press, 1993); L Goodman et al 'The Intimate Partner Violence Strategies Index: development and application' (2003) 9(2) Violence Against Women 163-186.

120. LE Walker The Battered Women Syndrome (New York: Springer, 1984).

121. Dutton, above $\mathrm{n} 117$.

122. Walker, above nn $114,115$.

123. ED Krause et al 'Longitudinal factor structure of posttraumatic stress symptoms related to intimate partner violence' (2007) 19(2) Psychol Assessment 165-175.

124. Dutton, above $\mathrm{n} 117$, at 6 .

125. Ibid.

126. MA Dutton et al 'Traumatic responses among battered women who kill' (1994) 7(4) J Traumatic Stress 549-564. 
sufficiently severe to merit a clinical diagnosis. ${ }^{127}$ Indeed, at times such a clinical diagnosis may be unhelpful, as it may characterise as 'abnormal' a series of responses that should rightly be viewed as reasonable. Yet the courts are seemingly alive to the importance of more minor symptoms, at least as they relate to battered women who kill, as evidenced by the judgment of Lord Justice Rose in $R v$ Smith, when he accepted that 'more minor symptoms are relevant to provocation, ${ }^{128}$ when they may not be to diminished responsibility'. ${ }^{129}$

That BWS has played such an important role in the direction that the criminal law has taken with regard not only to a series of high-profile cases but also the revised statutory approach to provocation/loss of control, is perhaps surprising given the apparent reluctance of law makers to engage with diagnostic issues. Yet the purpose of highlighting the inclusion of a diagnostically weak 'syndrome' in the courts' considerations is not to criticise. That the courts can rightly claim to have helped shape the evolution of research into the psychological impact of domestic abuse while simultaneously establishing which symptoms are of particular relevance in a legal context is perhaps the best example of the legal profession engaging with mental health sciences in a proactive way. The adoption of such a nuanced and engaged understanding in relation to domestic abuse stands in stark contrast to the passive acceptance of the diagnostic guidelines in relation to psychiatric injury generally. Crucially, this approach would seem to undermine concerns regarding the practicality of devising a set of diagnostic guidelines for legal purposes.

\section{CONCLUSION}

The retention of 'recognisable psychiatric injury' as the de minimis threshold for both a successful claim in negligence, and prosecution under the 1861 Act, has received extensive scholarly criticism, with repeated calls having been made for a new threshold inclusive of more minor symptoms. While there is undoubtedly merit in discussing the possible inclusion of more minor symptoms, this paper contends that the main problem caused by retention of such a high threshold is the increasingly passive position adopted by the Law Commission and legislators regarding expert testimony and, by extension, the diagnostic guidelines that help mental health practitioners to diagnose psychiatric conditions. Of central concern is the difficulty inherent in adequately incorporating this medical knowledge in a legal setting that places different emphasis on the importance of reliable diagnoses than that which is seen in normal clinical settings. This has resulted in repeated disagreements between experts as to the correct diagnosis, leading to conflicting testimony and inconsistencies in levels of judicial support for such evidence.

In spite of this, the Law Commission and certain judges have seemingly been convinced of the central importance of the diagnostic guidelines, noting their importance to the mental health professions. Yet it is crucial to note that any importance attached to these criteria by mental health practitioners is predicated on their utility in a clinical setting, not a legal one. Further, as has been discussed, universal acceptance of the diagnostic criteria amongst mental health professionals is a debatable point, particularly

127. LM Short et al 'Survivors' identification of protective factors and early warning signs for intimate partner violence' (2000) 6(3) Violence Against Women 272-285.

128. Note that this case occurred before the new loss of control defence came into being; hence the reference to provocation.

129. $R v$ Smith [2002] EWCA Crim 2671 at 40 (Rose LJ). 
following publication of the DSM-5, which seems set to exacerbate these pre-existing difficulties concerning the application of medical knowledge within a legal setting. In light of this, continued attempts to rely on these diagnostic guidelines in a legal context are analogous with trying to fit a square peg into a round hole. The most obvious solution to this problem is the development of new diagnostic guidelines specifically designed for use in a legal setting. Such a suggestion has previously been dismissed as impractical, and yet - as has been demonstrated - the courts' proactive participation in establishing BWS as a relevant consideration in domestic abuse cases, despite its omission from the DSM, would seem to confirm both the practicality and importance of properly adapting medical knowledge before attempting to apply it in court. 